\title{
Digital nerve conduction in the carpal tunnel syndrome after mechanical stimulation of the finger
}

\author{
J. G. MCLEOD ${ }^{1}$ \\ From the Institute of Neurology, Queen Square, London
}

In 1959 Sears showed that it is possible to record from human digital nerves the afferent volleys evoked by the physiological stimulus of a light tap on the fingernail. Subsequently, Bannister and Sears (1962) used the technique in studying the recovery of nerve conduction in a patient with acute idiopathic polyneuritis. This method of initiating volleys by stimulating peripheral mechanoreceptors has been employed in the present investigation to determine the conduction velocity of volleys in the digital nerves of control subjects and of patients with the carpal tunnel syndrome. It is known that in this condition there is slowing of motor conduction (Simpson, 1956; Thomas, 1960) and of sensory conduction (Gilliatt and Sears, 1958) across the compressive lesion at the wrist, but measurements of the conduction velocity in the digital nerves distal to the lesion have not previously been made.

A brief account of this work has already been published (McLeod, 1965).

\section{METHODS}

The subject sat with the pad of the middle finger resting lightly on a wooden block. A light tap was delivered approximately once a second to the finger nail by a nylon button on the end of a rod attached to an electromechanical transducer (Goodman type V 47) energized by a 9 volt battery (Fig. 1). The transducer and rod could be screwed up and down in a vertical plane, and, by varying the distance of the tip of the button from the finger nail, the displacement of the finger caused by the applied mechanical stimulus could be adjusted. The transducer was operated through a relay by pulses derived from a Digitimer (Devices Ltd.) which was also used to trigger the time base of the oscilloscope.

The onset of the stimulus was signalled from a piezoelectric ceramic transducer placed on the block beneath the pad of the finger. The output from this was mixed with the time-scale, and the first deflection was taken to indicate the moment of impact and thus the beginning of the mechanical stimulus to the finger. Shielding of the ceramic was necessary to prevent its signal being picked
up by the recording electrodes on the finger.

Recordings were made through electrodes of tinned $\vec{O}$ copper wire (S.W.G. 24) wrapped around the finger at threesites: the middle of the proximal phalanx, immediately $\vec{\omega}$ distal to the proximal interphalangeal joint, and just proxi- mal to the distal interphalangeal joint (Fig. 2). The hand was first thoroughly washed and warmed in hot water, electrode jelly was applied to the skin, and after applica-ĩ tion to the finger each electrode was covered with:adhesive cellulose tape to prevent drying and excessity $\vec{N}$ movement.

With mechanical stimulation, monopolar recording were made in turn from each electrode on the finger wi reference to a plate on the back of the hand, one of the other electrodes on the finger being earthed. Whern recording the reponses at the wrist, two electrodes $4 \mathrm{cof}$

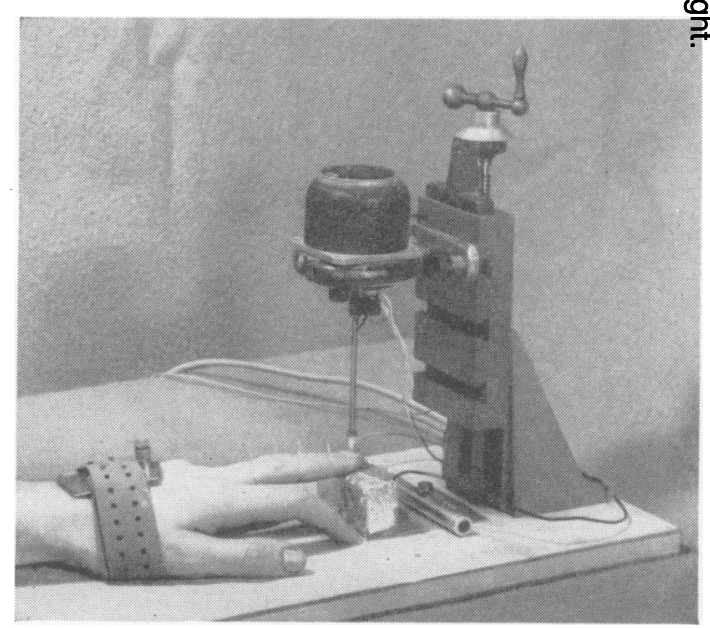

FIG. 1. The electromechanical transducer used for delivering a mechanical stimulus to the finger-nail. The pad of the finger rests on a shielded piezo-electric ceramic transducer supported by a wooden block. Three wire N recording electrodes are wrapped around the finger and $a$ metal plate on the back of the hand acts as a remote electrode. 
apart were placed over the median nerve; because of the difficulty in obtaining adequate muscular relaxation, bipolar recording was more satisfactory at this site than monopolar recording.

In a number of subjects the antidromic volley was recorded from the digital nerves following electrical stimulation of the median nerve at the wrist, and recordings were made in turn from each of the three electrodes, as described by Sears (1959). A condenser discharge of time constant $50 \mu \mathrm{sec}$. derived from a thyratron stimulator was applied to electrodes at the wrist with reference to a fourth electrode applied to the tip of the finger; the subject was earthed through the metal plate on the back of the hand.

The recording electrodes were connected to the input of a Tektronix FM 122 preamplifier and the responses displayed on the upper beam of a Tektronix 502 oscilloscope, the time scale and stimulus marker being displayed on the lower beam. Usually 50 traces were superimposed photographically on $35 \mathrm{~mm}$. film, but averaged responses have also been recorded using a barrier-grid storage tube (Gilliatt, Melville, Velate, and Willison, 1965).

At the end of each examination the distance between the electrodes was measured to the nearest millimetre, and the surface temperature was measured with a thermistor on the proximal phalanx of the finger from which recordings had been taken. In all cases the temperature ranged from $32^{\circ} \mathrm{C}$. to $35^{\circ} \mathrm{C}$.

For analysis of records, the film was placed in an enlarger and measurements made on the projected traces. Latencies to the onset of the first negative deflection and to the peak of the response were measured to the nearest $0 \cdot 1 \mathrm{msec}$. It was usually possible to measure the latency from the stimulus to the peak of the response more accurately than to the onset of the first negative deflection, and in six of the control subjects, and in two of those with carpal tunnel syndrome, no accurate measurements of latency to the initial negative deflection could be made. In all subjects, conduction velocities were calculated between the proximal and distal recording electrodes, a distance of about $4 \mathrm{~cm}$.

\section{FINDINGS IN CONTROL SUBJECTS}

CONDUCTION VELOCITY OF VOLLEYS EVOKED BY NAIL TAPPING Superimposed photographic records of compound action potentials recorded from successive sites along the middle finger, and from the median nerve at the wrist are shown in Fig. 2 and are similar in appearance to those obtained by Bannister and Sears (1962). It can be seen that the compound action potential recorded from a monopolar electrode on the finger with reference to a remote electrode on the back of the hand consists of a negative (upgoing) deflection followed by a positive phase. This whole response is superimposed on a non-propagated positive wave, which is more clearly defined after the propagated action potential has been reduced in amplitude by a period of ischaemia or by interaction with an antidromic volley as described by Sears (1959). Because of the presence
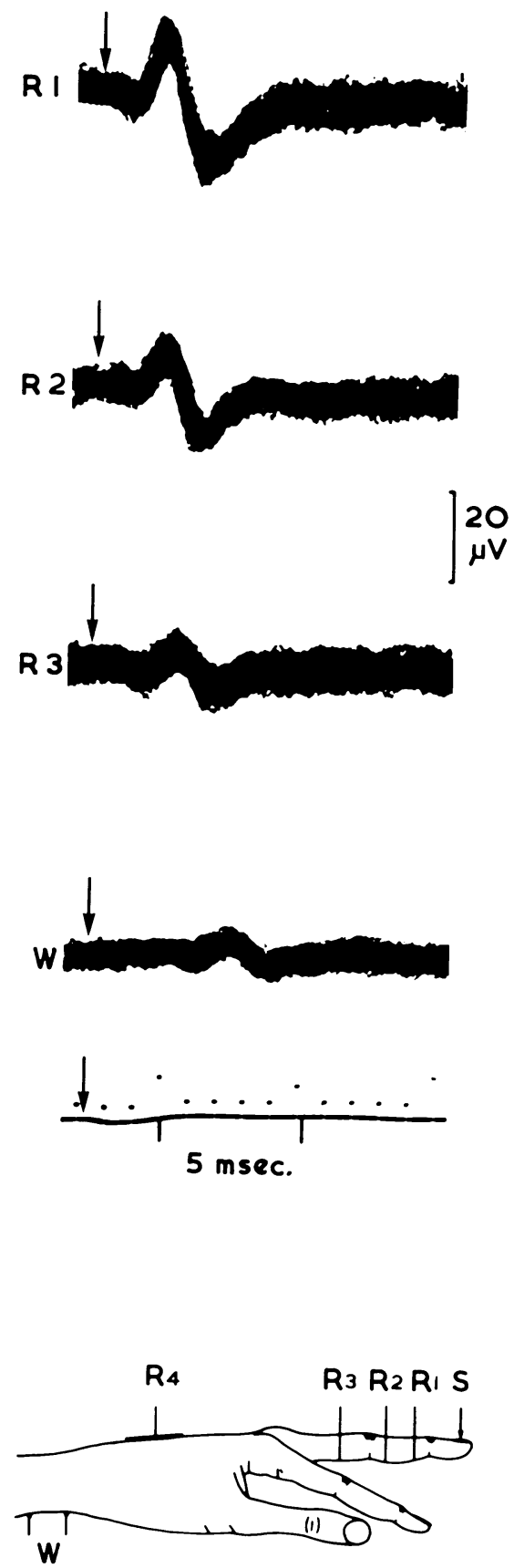

FIG. 2. Control subject. Action potentials evoked by mechanical stimulation $(S)$ recorded from successive sites, $R I, R 2, R 3$, on the finger with reference to a distant electrode $R 4$ on the back of the hand, and from $W$ at the wrist with a bipolar electrode. Arrows show the commencement of mechanical stimulus, as indicated by onset of deflection on time scale. Fifty consecutive traces superimposed. 
of the non-propagated wave, it is difficult to be certain whether or not the slight positivity preceding the main negative deflection (well seen in Fig. 2, $\mathrm{R} 1$ ) is propagated or not.

A light tap, which is only just perceptible to a healthy subject, is sufficient to produce a small response. The amplitude of the action potential increases in size with increasing displacement of the finger produced by the mechanical stimulus. The maximum amplitude of the response was usually attained when the displacement of the finger was about $0.5 \mathrm{~mm}$. At the start of each examination the distance of the top of the stimulator from the finger nail was adjusted until a response of maximum amplitude was obtained, but because of slight degrees of finger movement, readjustment was usually necessary at intervals during the procedure. However this did not affect the latency of the response which at any recording site remained constant over a wide range of amplitude.

It can be seen from Fig. 2 that the duration of the rising phase of the action potential from the first negative deflection to peak is of the order of $1 \mathrm{msec}$., which is considerably longer than the rising phase of the antidromic potential recorded from the finger after electrical stimulation of the median nerve at the wrist (Fig. 3) in which it is about $0.5 \mathrm{msec}$. This is probably due to asynchronous excitation of the mechano-receptors in the finger when it is deformed by the mechanical stimulus.

The conduction velocity of the volley in the digital nerves evoked by nail tapping was determined in 29 control subjects, eight of whom were healthy people and the remainder hospital patients without symptoms or signs related to the peripheral nerves (Table I). In every subject responses were recorded

TABLE I

$\begin{array}{lr}\text { CLINICAL DIAGNOSIS IN } 29 \text { CONTROL } & \text { SUBJECTS } \\ \text { Cerebrovascular disease } & 11 \\ \text { Healthy subjects } & 8 \\ \text { Idiopathic epilepsy } & 2 \\ \text { Cerebral tumour } & 2 \\ \text { Trigeminal neuralgia } & 2 \\ \text { Muscular dystrophy } & 1 \\ \text { Facial palsy } & 1 \\ \text { Labyrinthitis } & 1 \\ \text { Syringobulbia } & 1\end{array}$

from three sites on the finger (Fig. 2). The latencies to peak and, where possible, to the first negative deflection of the action potential, were measured and the conduction velocity calculated over the distance between electrodes. The results are summarised in Table II, from which it can be seen that when measured to the onset of the first negative deflection of the response conduction velocity in the digital nerves for the control subjects ranged from
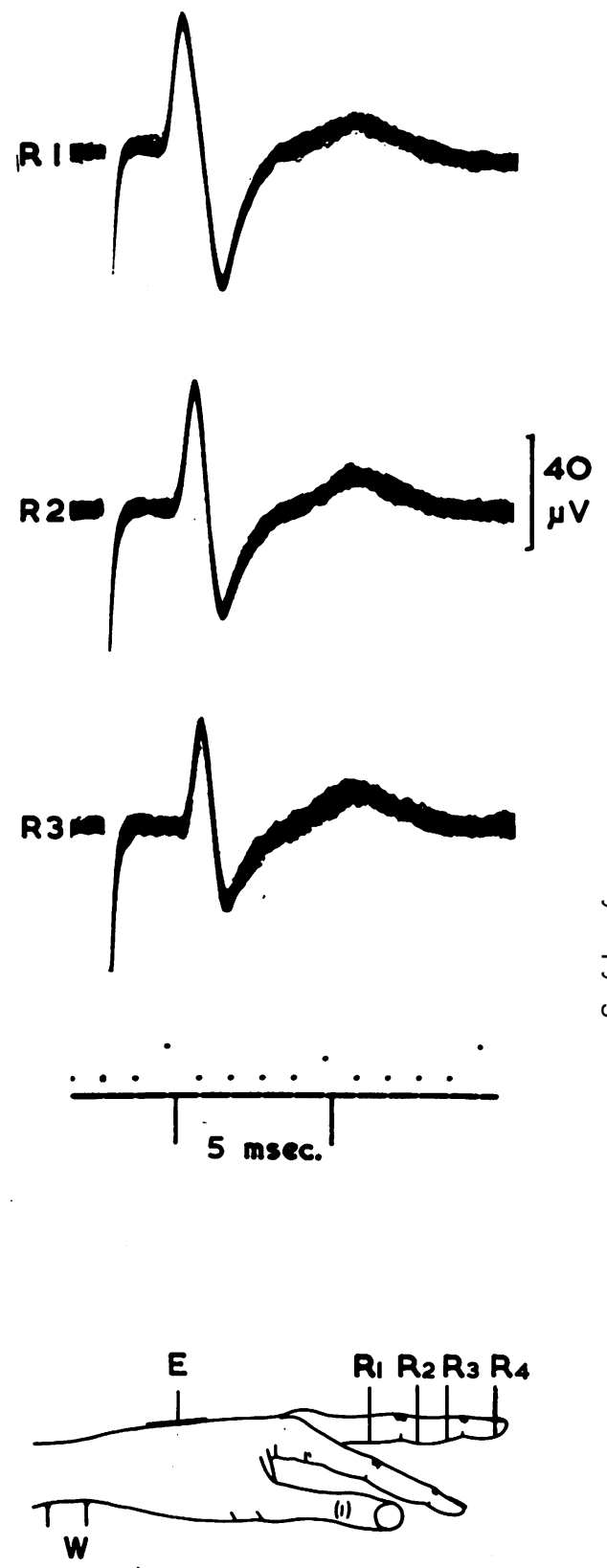

FIG. 3. Control subject. Antidromic volleys following $\frac{D}{\mathrm{D}}$ electrical stimulation of the median nerve at the wrist, $W$, recorded from sites $R 1, R 2, R 3$ on the finger with referencen to a distally placed electrode, R4. The late wave arises from distal muscle activity. Twenty consecutive traces $N$ superimposed. 
$36 \mathrm{~m} . / \mathrm{sec}$. to $67 \mathrm{~m} . / \mathrm{sec}$. (mean $50.4 \mathrm{~m}$./sec.; S.D., $8 \cdot 0$ ). Conduction velocity determined from measurements of latency to the peak of the response ranged from $40 \mathrm{~m} . / \mathrm{sec}$. to $67 \mathrm{~m}$./sec. (mean $51.8 \mathrm{~m}$./sec.; S.D., 6.4). There is no significant difference between these two values, suggesting that little dispersion takes place over the short conduction distance along the finger. However, Dawson (1956) has shown that there is a small difference in conduction time of the sensory action potential in the median nerve between wrist and elbow when measuring latencies in these two ways, indicating that in normal subjects some dispersion becomes evident over longer conduction distances.

In 20 of the 29 control subjects a small action potential was also recorded from the median nerve at the wrist (Fig. 2). In these subjects the mean conduction velocity over the palmar segment of the digital nerves between the proximal finger electrode and the wrist ranged from $40 \mathrm{~m}$./ $/ \mathrm{sec}$. to $65 \mathrm{~m}$. $/ \mathrm{sec}$. (mean $52.2 \mathrm{~m}$./sec.; S.D., 6.0) when measured from the latencies to the peak of the response.

The amplitude of the negative phase of the action potential at the distal finger electrode ranged from $4 \mu \mathrm{V}$ to $18 \mu \mathrm{V}$ (mean $10 \cdot 1 \mu \mathrm{V}$ ), and at the proximal electrode from $2 \mu \mathrm{V}$ to $8 \mu \mathrm{V}$ (mean $3.9 \mu \mathrm{V}$ ) in the control subjects. The amplitude of the action potential at the wrist was $1 \mu \mathrm{V}$ to $3 \mu \mathrm{V}$ (mean $2.0 \mu \mathrm{V}$ ); because of its small size in relation to the background activity, good musuclar relaxation was required for it to be recorded.

CONDUCTION VELOCITY OF ANTIDROMIC VOLLEYS IN DIGITAL NERVES FOLLOWING ELECTRICAL STIMULATION OF THE MEDIAN NERVE AT THE WRIST Sears (1959) first described the technique of recording antidromic volleys in the digital nerves, and this was subsequently applied to the study of nerve conduction in peripheral nerve lesions (Bannister and Sears, 1962; Campbell, 1962). In the present study, the antidromic action potentials following electrical stimulation of the median nerve at the wrist were recorded at successive sites along the middle finger in 17 control subjects, and the conduction velocity in the digital nerves calculated. Typical responses recorded from one subject are shown in Fig. 3 and the results summarized in Table II. When the latency was measured to the onset of the first negative deflection, the conduction velocity ranged from 44 $\mathrm{m} . / \mathrm{sec}$. to $62 \mathrm{~m}$./sec. (mean $51.3 \mathrm{~m} . / \mathrm{sec}$.; S.D., 4.9) and when the latency was measured to the peak of the response it ranged from $41 \mathrm{~m}$. $/ \mathrm{sec}$. to $68 \mathrm{~m}$. $/ \mathrm{sec}$. (mean 51.3 m./sec.; S.D., 6.5).

EFFECT OF ISCHAEMIA ON DIGITAL NERVE CONDUCTION In order to provide further evidence that the responses recorded from the finger following mechanical stimulation represented activity in the digital nerves rather than a transmitted mechanical artefact, the effect of ischaemia was studied.

In four subjects, a sphygmomanometer cuff was inflated around the upper arm to a pressure of about $200 \mathrm{~mm}$. $\mathrm{Hg}$ for a period up to 30 minutes. Figure 4 shows the reduction in amplitude and increase in duration of the response to mechanical stimulation which occurred with ischaemia in one subject, and similar results were seen in the other three subjects. After 25 to $\mathbf{3 0}$ minutes of ischaemia, no antidromic action potentials could be recorded from the finger with electrical stimulation at the wrist. However, at this time a small response to mechanical stimulation could be recorded at the most distal electrode on the finger but not at the next electrode $2 \mathrm{~cm}$. proximally, indicating that dispersion of the action potential was responsible for its failure to be recorded over longer conduction distances.

The dispersion of the action potential caused by ischaemia is shown graphically in Fig. 5a, in which the conduction velocity calculated from measurements of latency to the onset of the negative deflection is compared with that calculated from measurements of latency to the peak. Before ischaemia there is little difference between the two values ( 51 $\mathrm{m}$./sec. and $54 \mathrm{~m}$./sec. respectively) but after 19

TABLE II

DIGITAL NERVE CONDUCTION VELOCITIES IN THE FINGERS OF CONTROL SUBJECTS AND OF PATIENTS WITH CARPAL TUNNEL SYNDROME

Mechanical Stimulation of Finger

Latency Measured to Onset of Negative Deflection of Action Potential

Control subjects
Carpal tunnel syndrome

Range: $36-67 \mathrm{~m} . / \mathrm{sec} .(23)^{1}$ Mean: $50.4 \mathrm{~m} . / \mathrm{sec}$. (S.D., 8.0)

Range: $21-60 \mathrm{~m}$./sec. (20) Mean: $41.0 \mathrm{~m} . / \mathrm{sec}$. (S.D. 11.4)
Latency Measured to Peak of Action Potential

Range: $40-67 \mathrm{~m} / \mathrm{sec}$. (29)

Mean: $51.8 \mathrm{~m}$./sec. (S.D., 6.4)

Range: $17-55 \mathrm{~m} . / \mathrm{sec}$. (22)

Mean: $33.0 \mathrm{~m} . / \mathrm{sec}$. (S.D. 10.6)
Electrical Stimulation at Wrist

Latency Measured to Onset of

Negative Deflection

Range: 44-62 m./sec. (17)

Mean: $51 \cdot 3 \mathrm{~m} . / \mathrm{sec}$. (S.D., 4.9)

${ }^{1}$ Numbers in brackets after range of conduction velocities refer to the number of patients in each group. 

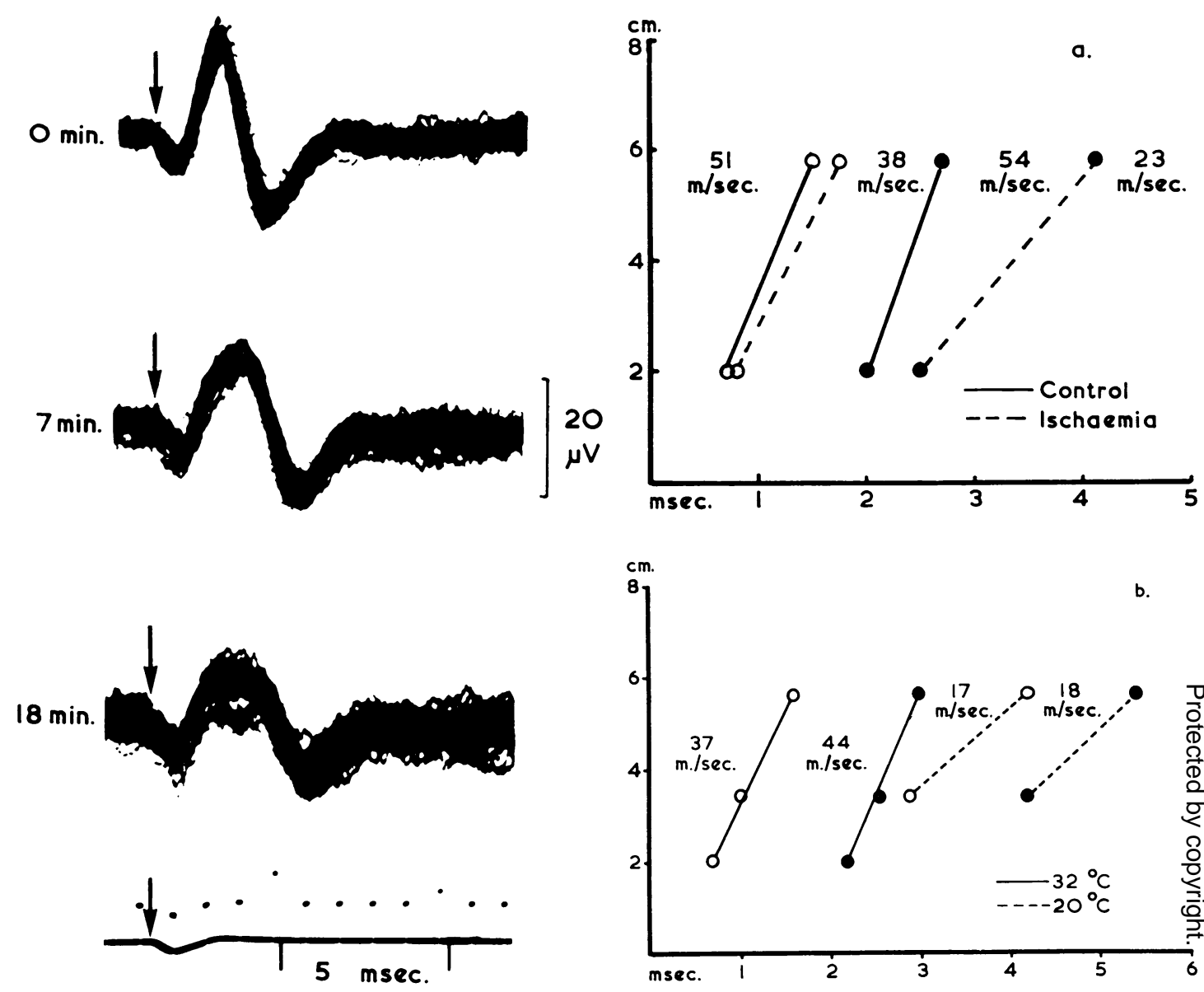

FIG. 4.

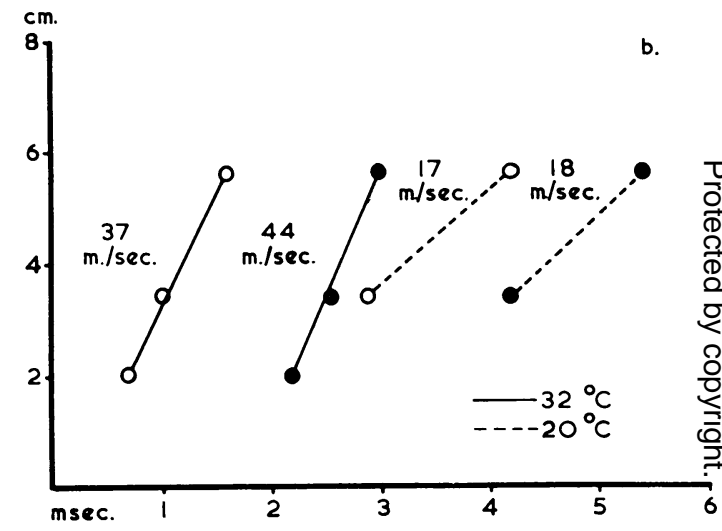

FIG. 5 .

FIG. 4. Control subject. Effect of 18 minutes of ischaemia on action potentials evoked by mechanical stimulation of the finger. Recordings made from electrode position RI (Figure 1). Sphygmomanometer cuff around upper arm inflated to pressure of $200 \mathrm{~mm}$. Hg. Fifty consecutive traces superimposed.

FIG. 5. Control subject. Graphs showing effect of $(a) 18$ minutes of ischaemia and $(b)$ change in temperature from $20^{\circ} \mathrm{C}$. to $32^{\circ} \mathrm{C}$. on conduction velocity of the action potential evoked by mechanical stimulation of the finger. The latency of 3 each action potential is plotted against the conduction distance along the finger; the conduction velocity is given by the $\overrightarrow{7}$ slope of the lines.

Open circles represent measurements of latency to the onset of the negative deflection of the action potential; closed circles represent measurements of latency to the peak of the action potential.

minutes of ischaemia the peak velocity is disproportionately slowed $(23 \mathrm{~m} . / \mathrm{sec}$, compared with 38 $\mathrm{m} . / \mathrm{sec}$.) indicating that rapid temporal dispersion of the volley has occurred.

EFFECT OF COOLING ON DIGITAL NERVE CONDUCTION In two subjects the effect of cooling the hand on the action potential in the digital nerves following mechanical and electrical stimulation was observed. The hand was first placed in iced water for about 10 minutes, and, after drying, the electrodes were placed in position and recordings made in the usual way. 을 The hand was then warmed to 31 to $32^{\circ} \mathrm{C}$. and $₹$ further series of recordings made. In one of the subjects control records were also made at the start of the experiment before the hand was cooled. In $\underline{\text { O }}$ both cases the amplitudes of the responses to both types of stimulation were 10 to $20 \%$ greater at the $\Omega$ lower temperatures. Marked alterations in conduc- N tion velocity occurred with changes in temperature, N 
in one subject the conduction velocity being slowed by a factor of $2.8 \mathrm{~m} . / \mathrm{sec}$. per $1_{1} \mathrm{C} .\left(\mathrm{Q}_{10}=2 \cdot 3\right)$ and in the other by $2.4 \mathrm{~m}$./sec. per $1^{\circ} \mathrm{C}$. $\left(Q_{10}=2 \cdot 1\right)$. Although the rising phase of the action potential was prolonged by cooling, the conduction velocities calculated from latencies to its foot and peak were affected to a similar degree (Fib. 5b), indicating that the large myelinated fibres contributing to the action potential were uniformly affected by changes in temperature. This may be contrasted with the dispersion which occurs with ischaemia, as described in the previous section.

FINDINGS IN PATIENTS WITH CARPAL TUNNEL SYNDROME

Digital nerve conduction velocities were determined following mechanical stimulation at the finger in 21 subjects with the carpal tunnel syndrome, one of whom had bilateral median nerve involvement. In all the patients the clinical diagnosis was confirmed by conventional motor and sensory nerve conduction studies (Simpson, 1956; Gilliatt and Sears, 1958; Thomas, 1960), the results of which are summarized in Table III.

The action potentials recorded from successive sites along the finger are similar in appearance to those obtained in control subjects, and typical responses recorded in one of the patients are shown in Figure 6. When the latency was measured to the onset of the first negative deflection of the response, conduction velocities ranged from $21 \mathrm{~m}$./ $/ \mathrm{sec}$. to $60 \mathrm{~m}$./sec. (mean $41 \mathrm{~m} . / \mathrm{sec}$.; S.D., 11.4), and when the latency was measured to the peak of the response they ranged from $17 \mathrm{~m}$./ $/ \mathrm{sec}$. to $55 \mathrm{~m}$. $/ \mathrm{sec}$. (mean $33.0 \mathrm{~m}$. $/ \mathrm{sec}$.; S.D., 10.6). These results are summarized in Table II. In contrast to the findings in control subjects, there was a significant difference in the conduction velocities determined in these two ways, and this is shown graphically in Fig. 7 for two individual cases. It is concluded from these results that dispersion takes place more rapidly over short conduction distances in patients with median nerve lesions at the wrist than in control subjects.

The amplitudes of the action potentials at the distal finger electrodes in patients with the carpal tunnel syndrome were 3-20 $\mu \mathrm{V}$ (mean 9.5 $\mu \mathrm{V}$ ) and at the proximal electrode 2-9 $\mu \mathrm{V}$ (mean $3.9 \mu \mathrm{V}$ ) and these do not differ significantly from the controls. However, no action potentials could be recorded at the wrist in response to nail-tapping in any of the patients with the carpal tunnel syndrome, although this was possible in 20 out of the 29 controls.

The conduction velocities derived from measurements of latency to the peak of the response of both the control group and the patients with carpal tunnel syndrome are plotted against age in Fig. 8, in which it can be seen that although in some cases of carpal tunnel syndrome the digital nerve conduction velocity falls within the normal range, in the majority it

TABLE III

Patient Age Motor Conduction

\begin{tabular}{ll}
\hline Latency: wrist- & Conduction Velocity \\
$A P B($ msec.) & in Median Nerve in \\
& Forearm $(\mathrm{m} . / \mathrm{sec})$.
\end{tabular}

Sensory Conduction

\begin{tabular}{lll}
\hline $\begin{array}{l}\text { Sensory Action Potential } \\
\text { at Wrist (Electrical } \\
\text { Stimulation of Index } \text { Finger) }\end{array}$ & $\begin{array}{l}\text { Digital Nerve } \\
\text { Conduction Velocity } \\
(\text { Mechanical Stimulation) } \\
(\text { m./sec. })^{1}\end{array}$ \\
\hline $\begin{array}{l}\text { Latency } \\
(\text { msec.) }\end{array}$ & $\begin{array}{l}\text { Amplitude } \\
(\mu V)\end{array}$ & \\
\hline
\end{tabular}

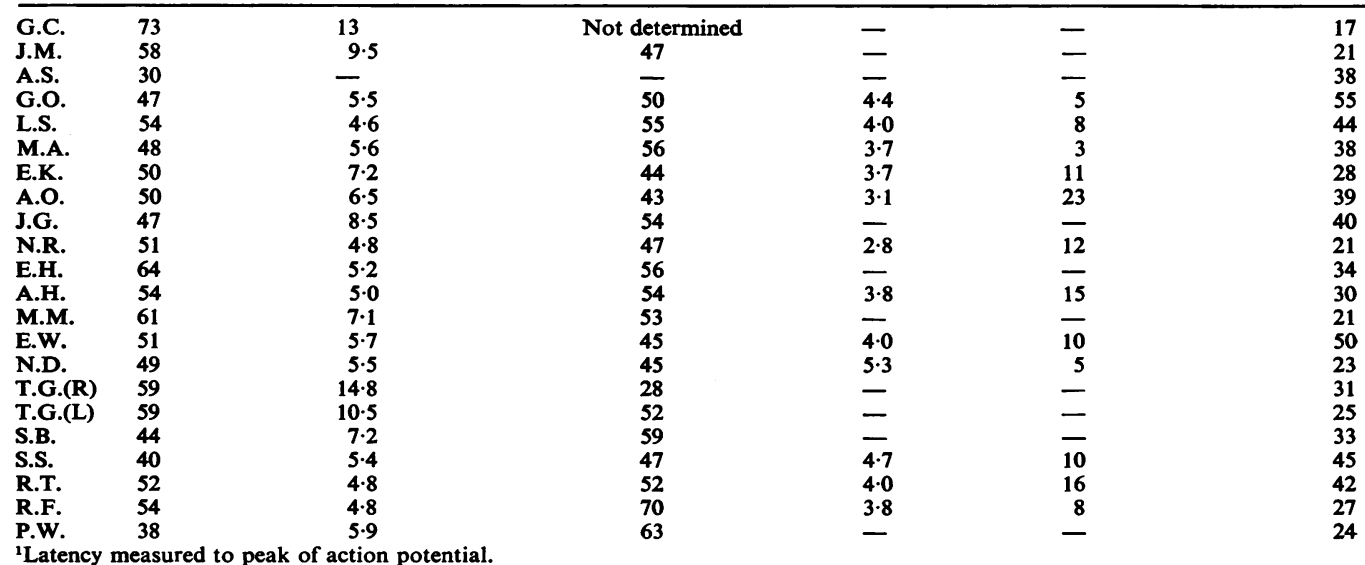



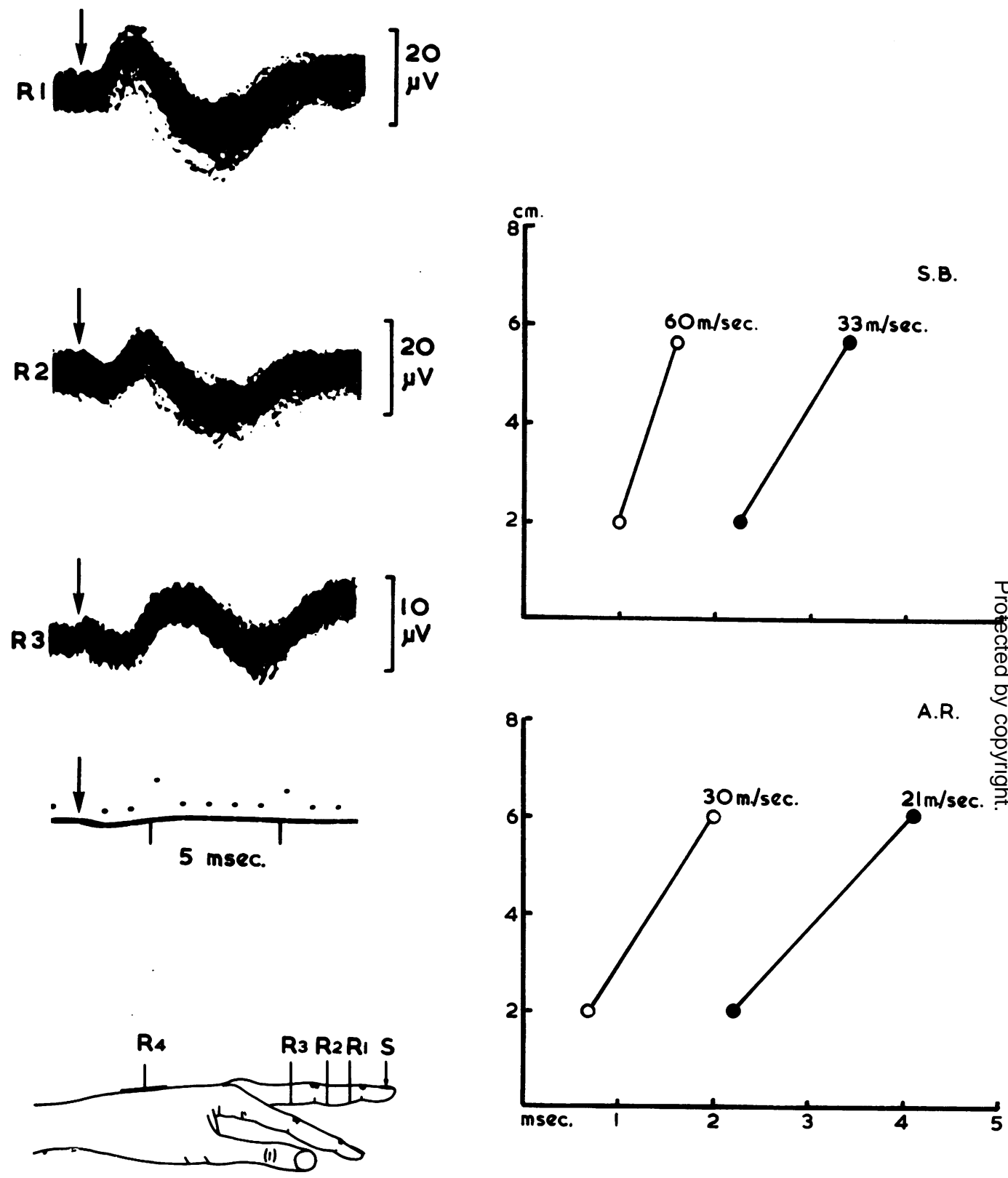

FIG. 7. Carpal tunnel syndrome. Graphs for two subjects showing latency of the action potential evoked by mechani-

FIG. 6. Carpal tunnel syndrome. Action potentials evoked by mechanical stimulation $(S)$ recorded from successive sites, $R 1, R 2, R 3$, on the finger with reference to a distant electrode, R4, on the back of the hand. Arrows show the commencement of mechanical stimulus as indicated by onset of deflection on time scale. Fifty consecutive traces superimposed. cal stimulation plotted against conduction distance along the finger. The conduction velocities are given by the slope $\frac{1}{0}$ of the lines.

Open circles represent measurements of latency to the $N$ onset of the negative deflection of action potential; closed circles represent measurements of latency to the peak of $\mathrm{N}$ the action potential. 


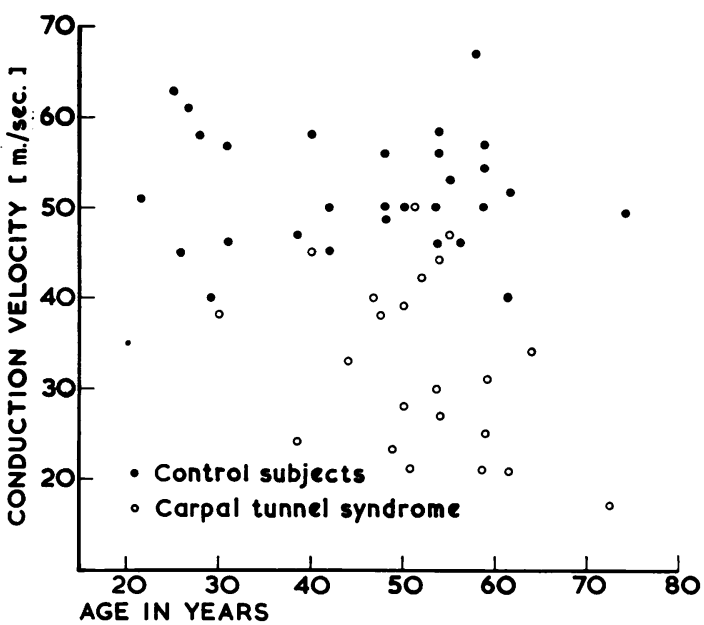

FIG. 8. Conduction velocities of volleys in digital nerves evoked by mechanical stimulation in control subjects (closed circles) and in patients with carpal tunnel syndrome (open circles) plotted against age of subject. Measurements of latency taken to peak of action potential.

is slowed. There is also some relationship in these patients between the size of the sensory action potential recorded from the median nerve at the wrist on electrically stimulating the index finger, as described by Gilliatt and Sears (1958), and the conduction velocity of volleys in the digital nerves evoked by nail tapping. From Fig. 9 it can be seen that in nine of the 10 instances in which no action potential could be recorded at the wrist on electrical stimulation, the digital nerve conduction velocity was below the normal range. In the 12 patients with carpal tunnel syndrome in whom a sensory action potential was recorded at the wrist, the digital nerve conduction velocities in five were within the normal range, but fell below it in the remainder. In the 10 patients in whom action potentials were absent at the wrist, antidromic volleys could not be recorded from the finger.

EFFECT OF SURGICAL DIVISION OF FLEXOR RETINACULUM ON DIGITAL NERVE CONDUCTION In four subjects digital nerve conduction was determined at intervals following surgical division of the flexor retinaculum. There was a progressive increase in the conduction velocity which paralleled the increase of the motor conduction velocity in the median nerves, and the return to normal range of amplitude and latency of the sensory action potential in the median nerve at the wrist which followed electrical stimulation of the finger. Figure 10 shows the increase in digital nerve conduction velocity which occurred

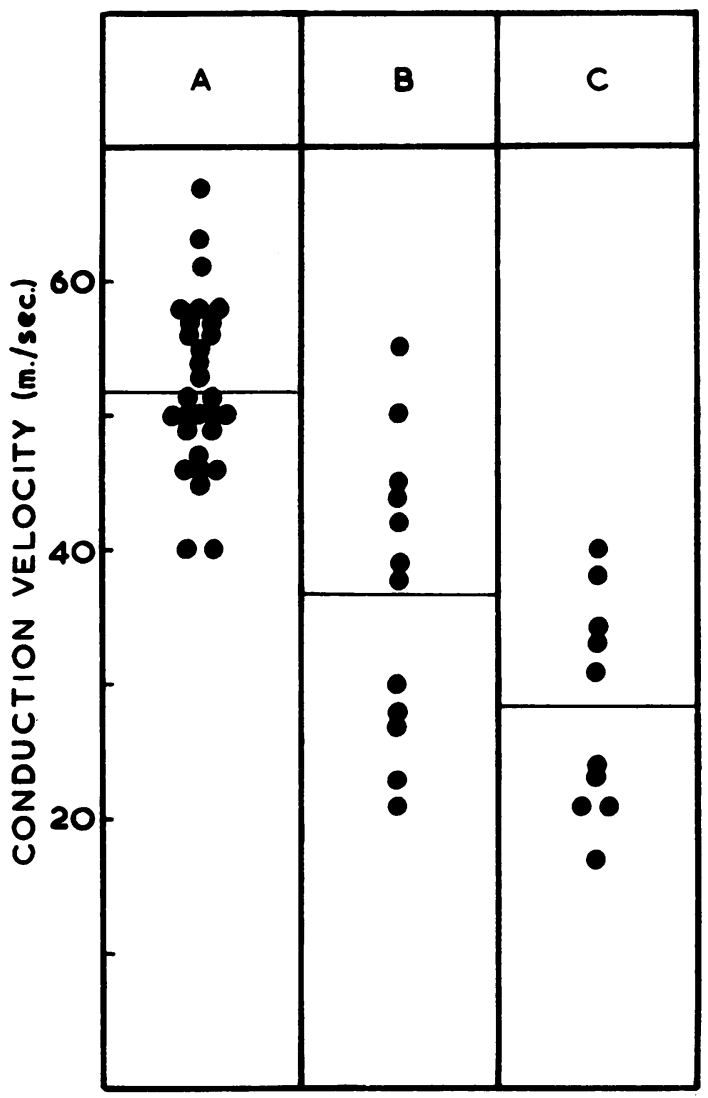

FIG. 9. Conduction velocities of volleys in digital nerves evoked by mechanical stimulation in :

$A$ Control subjects

$B$ Patients with carpal tunnel syndrome in whom an action potential is recordable at the wrist on electrical stimulation of the index finger.

C Patients with carpal tunnel syndrome in whom no action potential is recordable at the wrist on electrical stimulation of the index finger.

Horizontal lines represent the mean conduction velocity for each group.

after operation in one of the patients observed for the longest period of time (eight months). At the end of this time the digital nerve conduction velocity was $38 \mathrm{~m}$./sec. which is just below the lowest value of the control range. This figure might have increased further if a longer period of observation had been possible, but it is of interest in this regard that Goodman and Gilliatt (1961) found that complete restoration of normal motor conduction did not occur during a longer follow-up period in patients with severe and moderately severe pre-operative conduction defects. 


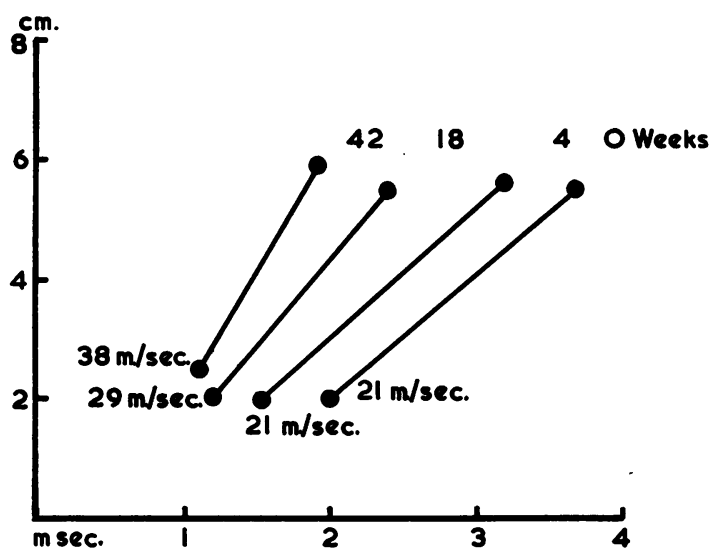

FIG. 10. Carpal tunnel syndrome. Graph showing increase in digital nerve conduction velocity in one subject at intervals of $0,4,18$, and 42 weeks following surgical division of the flexor retinaculum. Latency to the peak of the action potential evoked by mechanical stimulation is plotted against conduction distance along the finger. Conduction velocity is represented by the slope of the line.

\section{DISCUSSION}

A tap applied to the finger nail probably excites mechano-receptors not only in the nail bed and in the pad of the finger, but also in the subcutaneous tissues and deeper structures. According to Winkelmann (1960) the distal glabrous skin over the volar surfaces of the finger contains dermal networks from which arise myelinated fibres supplying herediform endings and Meissner's corpuscles. Pacinian corpuscles are found near the glomus body and the deeper subcutaneous tissue. The nail bed contains mainly unencapsulated nerve balls and nerve networks but no Meissner's corpuscles, although there are occasional Pacinian corpuscles. It is not possible to deduce from the present work which sensory endings are excited by nail tapping, but it was shown by Sears (1959) and has been confirmed in this investigation that the main deflection of the evoked response represents activity chiefly in the fastest conducting fibres of the digital nerves.

The conduction velocity in the digital nerves of orthodromic volleys evoked by nail tapping, and of antidromic volleys following electrical stimulation obtained in the present study are in close agreement with Sears' figure of $54 \mathrm{~m}$./sec., S.D., $4 \cdot 7$ (cited by Bannister and Sears, 1962), for the conduction velocity of antidromic volleys in the proximal phalangeal segments of the digital nerves. Rosenfalck and Buchthal (1964) have also studied the conduction velocities of volleys in sensory fibres in the upper limbs in man following electrical stimulation of the digital nerves; they found a mean conduction velo- $z$ city of $63.5 \mathrm{~m}$./ sec., but state that the velocity is $15-30 \%$ lower in the fingers, which agrees well with the present findings.

The main negative deflection of the action poten- 7 tial recorded from the finger with surface electrodes in response to both mechanical and electrical stimula- $-\frac{\overline{-}}{\mathrm{s}}$. tion is not preceded by an easily recognizable positive wave. In this it differs from the action poten-: tials recorded from the median, ulnar, and lateral $\overrightarrow{\vec{s}}$ popliteal nerves which usually display a more pronounced initial positive deflection (Dawson, 1956; Gilliatt, Goodman, and Willison, 1961; Gilliatt $\overline{\bar{s}}$. et al., 1965). This difference is probably explained $\overline{\widehat{D}}$ by the fact that the digital nerves lie superficially ${ }_{0}$ in the finger and close to the recording electrodes $\infty$ whereas the other nerves are more deeply situated $\overrightarrow{0}$ in a volume conductor and are at a greater distance $\overrightarrow{-}$ from the recording electrodes. The compound action $\omega$ potential recorded from the finger in response to mechanical stimulation can often be seen to be superimposed upon a positive wave which is not propa-in gated and which is of greatest amplitude at the most ${ }^{\circ}-$ distal recording electrode. The wave can be seen $\mathbb{H}_{\mathrm{j}} \overrightarrow{\mathrm{N}}$ relative isolation after a period of ischaemia or aftor 0 blocking of the propagated response by an anf dromic volley, and it probably represents a potea $\vec{T}$ tial generated by mechanical deformation of tissues.

The response to mechanical stimulation behaves in a similar manner to that following electrial stimulation under conditions of ischaemia and cooling. It has been previously demonstrated by $a^{\circ}$ number of workers (Magladery, McDougal, and Stoll, 1950; Cobb and Marshall, 1954; Fullerton, 乏 1963) that motor conduction is slowed after a periodo of ischaemia, and it is clear from the present work that sensory conduction is similarly affected. The rapid decay in amplitude of the antidromic action $\overrightarrow{\vec{F}}$ potential recorded from the finger after electrical 3 stimulation of the median nerve at the wrist and of $\vec{P}$ the orthodromic volley following nail tapping is? consistent with the findings of Magladery et al. (1950) and Gilliatt and Willison (1963) on the median nerve. The dispersion of the volley which occurred:indicates that the nerve fibres contributing to the 3 . action potential are not uniformly affected by ischaemia.

Henriksen (1956) found that cooling the ulnaro nerve over the range of 27 to $30^{\circ} \mathrm{C}$. caused a reduction in nerve conduction velocity by a factor of 2.4 음 $\mathrm{m}$./sec. per $1^{\circ} \mathrm{C}$. which is close to the figure of 2.4 to $2.8 \mathrm{~m}$. $/ \mathrm{sec}$. per $1^{\circ} \mathrm{C}$. found in the present investiga- $N$ tion. The temperature coefficient $\left(Q_{10}\right)$ calculated $N$ for the digital nerves in this investigation was N $2 \cdot 1-2 \cdot 3$, which is in close agreement with that of ${ }_{\sigma}^{\mathrm{W}}$ 
$2 \cdot 18$ found by Inman and Peruzzi (1961) in single nerve fibres in the cat. In the present experiments, it was found that the amplitude of the compound action potential following both electrical and mechanical stimulation was slightly greater at the lower temperatures. A similar effect was noted in the frog nerve by Lorente de Nó (1947) and in the cat's peripheral nerves by Kiraly and Krnjević (1959). In contrast to the effect of ischaemia, reduction in temperature causes conduction velocity to be slowed uniformly in the fibres contributing to the action potential.

In patients with the carpal tunnel syndrome Gilliatt and Sears (1958) showed that the sensory action potential recorded from the median nerve at the wrist following electrical stimulation of the index finger was reduced in amplitude and its latency to peak increased. In a number of patients, and particularly in those with obvious sensory defects, the action potential at the wrist was absent. They postulated that the abnormalities in the sensory action potential were most likely due to slowing of conduction in the large myelinated fibres, with the result that the action potential became dispersed and desynchronized; by the time impulses reached the recording electrodes at the wrist the action potential was reduced in amplitude or had wholly disappeared. In the present work it has been shown that considerable slowing of conduction can occur in the fast-conducting fibres below the level of the lesion at the wrist and that in general this has been most marked in those subjects in whom the action potential following electrical stimulation of the finger has been absent when recording at the wrist. By comparing the conduction velocities calculated from latencies to the onset of the negative deflection of the response with those calculated from latencies to the peak, it has been shown that rapid dispersion of the volley takes place along the finger in many cases. It seems likely, therefore, that slowing of conduction and temporal dispersion of the volley account for the failure to record an action potential over longer conduction distances. Gilliatt and Sears (1958) were unable to exclude the possibility that the reduction in amplitude of the action potential at the wrist following electrical stimulation was due to an increase in electrical threshold in the damaged fibres; however, by stimulating the sensory receptors in the finger by physiological means it has now been shown that this is not likely to be an important factor.

Gilliatt and Thomas (1960) demonstrated slowing of nerve conduction distal to chronic ulnar nerve lesions at the elbow. In the carpal tunnel syndrome conduction velocities in the nerve distal to the lesion have not previously been determined, since in pre- vious investigations only the motor and sensory conduction times across the compressed segment have been measured. The slowing of conduction found in the present investigation may be partly due to reduction in diameter of nerve fibres below the constriction (Thomas, 1960); although this may not be the only explanation for the marked slowing of conduction which occurred in some of the patients, reduction in fibre diameter in the digital nerves was certainly observed in the case examined histologically by Thomas and Fullerton (1963).

From the practical point of view, mechanical stimulation offers some advantages over electrical stimulation of the finger in that it allows conduction to be studied over short distances, a procedure which is unsatisfactory with electrical stimulation because of difficulty in controlling stimulus artefact. The measurement of conduction velocity over short conduction distances in the finger is of particular value in patients with neuropathies, when slowing and dispersion of the volley is of such a degree that an action potential cannot be recorded over the longer conduction distance between finger and wrist.

\section{SUMMARY}

The conduction velocities of volleys evoked by the physiological stimulus of a mechanical tap on the finger nail have been studied in the digital nerves of 29 control subjects and 21 patients with the carpal tunnel syndrome.

The conduction velocity in the digital nerves of the middle finger of the control subjects ranged from $40 \mathrm{~m}$. $/ \mathrm{sec}$. to $67 \mathrm{~m}$. $/ \mathrm{sec}$. (mean $51.8 \mathrm{~m}$./sec.; S.D., 6.4 ), and of the patients with the carpal tunnel syndrome from $17 \mathrm{~m}$./sec. to $55 \mathrm{~m}$./sec. (mean 33.0 $\mathrm{m} . / \mathrm{sec}$., S.D., 10.6), when the latency was measured to the peak of the response. In the patients with the carpal tunnel syndrome there was evidence of rapid dispersion of the volley over the short conduction distance along the finger; this was in contrast to the findings in the control subjects.

Digital nerve conduction was studied in four patients with the carpal tunnel syndrome at intervals after surgical division of the flexor retinaculum at the wrist, and a progressive increase in conduction velocity was found in all cases.

The effect of ischaemia and change in temperature on digital nerve conduction was also investigated.

I wish to thank Professor R. W. Gilliatt, Dr. T. A. Sears, and Dr. R. G. Willison for their advice, help, and encouragement. Mr. P. Fitch gave valuable technical assistance. The work was carried out during the tenure of a Nuffield Foundation Dominion Travelling Fellowship, 
and some of the apparatus used was provided from a personal grant to Professor Gilliatt from the Medical Research Council.

\section{REFERENCES}

Bannister, R. G., and Sears, T. A. (1962). The changes in nerve conduction in acute idiopathic polyneuritis. J. Neurol. Neurosurg, Psychiat., 25, 312-328.

Campbell, E. D. R. (1962). The carpal tunnel syndrome: investigation and assessment of treatment. Proc. Roy. Soc. Med., 55, 401405.

Cobb, W. A., and Marshall, J. (1954). Repetitive discharges from human motor nerves after ischaemia and their absence after cooling. J. Neurol. Neurosurg. Psychiat., 17, 183-188.

Dawson, G. D. (1956). The relative excitability and conduction velocity of sensory and motor nerve fibres in man. J. Physiol. (Lond.), 131, 436-451.

Fullerton, P. M. (1963). The effect of ischaemia on nerve conduction in the carpal tunnel syndrome. J. Neurol. Neurosurg. Psychiat., 26, 385-397.

Gilliatt, R. W., Goodman, H. V., and Willison, R. G. (1961). The recording of lateral popliteal nerve action potentials in man. J. Neurol. Neurosurg. Psychiat., 24, 305-318.

—, Melville, I. D., Velate, A. S., and Willison, R. G. (1965). A study of normal nerve action potentials using an averaging technique (barrier grid storage tube). Ibid., 28, 191-200.

_ and Sears, T. A. (1958). Sensory nerve action potentials in patients with peripheral nerve lesions. Ibid., 21, 109-118.

- and Thomas, P. K. (1960). Changes in nerve conduction with ulnar lesions at the elbow. Ibid., 23, 312-320.

-, and Willison, R. G. (1963). The refractory and supernormal periods of the human median nerve. Ibid., 26, 136-147.
Goodman, H. V., and Gilliatt, R. W. (1961). The effect of treatment on median nerve conduction in patients with the carpal tunnel syndrome. Ann. phys. Med., 6, 137-155.

Henriksen, J. D. (1956). Conduction velocity of motor nerves in normal subjects and patients with neuromuscular disorders. M.S. (Phys. Med.) Thesis, University of Minnesota.

Inman, D. R., and Peruzzi, P. (1961). The effects of temperature on the responses of Pacinian corpuscles. J. Physiol. (Lond.), 155, 280301

Kiraly, J. K. and Krnjević, K. (1959). Some tretrograde changes in function of nerves after peripheral section. Quart. J. exp. Physiol., 44, 244-257.

Lorente de Nó, R. (1947). A Study of Nerve Physiology, Part 2. Stud. Rockefeller Inst. med. Res., 132, 314-316.

Magladery, J. W., McDougal, D. B., and Stoll, J. (1950). Electrophysiological studies of nerve and reflex activity in normal man. II. The effects of peripheral ischemia. Bull. Johns Hopk. Hosp., 86, 291-312.

McLeod, J. G. (1965). Digital nerve conduction in man following $\overline{\bar{c}}$ mechanical stimulation of the finger. J. Physiol. (Lond.), 178, $30 \mathrm{P}$.

Rosenfalck, A., and Buchthal, F. (1964). Action potentials from sensory nerve. Electroenceph. clin. Neurophysiol., 17, 100.

Sears, T. A. (1959). Action potentials evoked in digital nerves by stimulation of mechanoreceptors in the human finger. $J$. Physiol. (Lond.), 148, 30-31P.

Simpson, J. A. (1956). Electrical signs in the diagnosis of carpal tunnel and related syndromes; J. Neurol. Neurosurg. Psychiat., 19, 275-280.

Thomas, P. K. (1960). Motor nerve conduction in the carpal tunnel syndrome. Neurology (Minneap.), 10, 1045-1050.

- , and Fullerton, P. M. (1963). Nerve fibre size in the carpal tunnel is syndrome. J. Neurol. Neurosurg. Psychiat., 26, 520-527.

Winkelmann, R. K. (1960). Nerve Endings in Normal and Pathologid:Skin. Thomas, Springfield, Illinois. 
LÄSIONEN PERIPHÄRER NERVEN. Diagnostik und Therapie. By M. Mumenthaler and H. Schliack. (Pp. xii + 348; 173 figures; 19 tables. DM.68.) Stuttgart: Georg Thieme Verlag. 1965.

Clinical neurologists expect to be able to define and localize any lesion of a peripheral nerve. In peace-time practice, however, many nerve lesions are only seen rarely, and for any clinician who wishes to perfect his methods and knowledge of peripheral nerve diseases and injuries this is a wonderfully comprehensive work of reference. The methods of testing the strength of each muscle are clearly illustrated and Table 8 (p. 164) deserves special mention, for here are displayed on one sheet the muscles of the upper extremity which are involved in every variety of peripheral nerve or plexus injury: a most ingenious presentation. The therapeutic problems receive relatively little attention, but from the surgical point of view the use of millipore in the bridging of gaps in a nerve is referred to.

W. RITCHIE RUSSELL

ARTERIAL diseaSe By J.R. A. Mitchell and C.J.Schwartz. (Pp. Xv + 411; illustrated. 95s.) Oxford: Blackwell Scientific Publications.

This book is a monument of careful observation and patient industry. The authors have made a necropsy study of the heart and major arteries in 293 unselected patients aged 35 years and over and in selected series with large areas of cardiac necrosis or scarring and diabetes. In addition they have studied the aorta in 43 patients aged 15 to 34 . They have described with meticulous care the morphology, localization, and correlation between the different types of arterial lesions in various sites with special emphasis on the aorta and on the coronary and carotico-vertebral arteries. The same care has been given to the study of the lesions found in the heart in ischaemic disease. The lesions are illustrated by high quality photomicrographs and the results tabulated in a large number of tables and histograms. This part of the book will remain as a standard work of reference for a long time to come.

Unfortunately, other parts of the work do not attain the same standard of excellence. The discussion of the mechanism of transient ischaemic attacks is far too brief and superficial to be of real value. The chapter on therapy is likewise inadequate; for example, in the section on anticoagulant therapy in transient focal cerebral attacks only one reference is given and no mention is made of the two controlled clinical trials of the Veterans Administration and the United States Public Health Service.

Despite these blemishes in the later sections the excellence of the earlier part of the book, which describes the original pathological work of the authors, makes it necessary reading for all interested in arterial disease.

CEREBRAL ISCHEMia By G. E. Simonson and T. H. McGavack. (Pp. XX + 299; illustrated. \$11.50.) Springfield, Illinois: Charles C. Thomas. 1964.

This is the report of a symposium presented to the American Gerontological Society at Miami Beach. A wide range of topics is covered including haemodynamics, the electroencephalogram in cerebral ischaemia, rheo- encephalography, and ophthalmodynamometry. Some contributions have attempted too much, as in one chapter which covers anatomy, pathology, symptomatology, dietary considerations, blood clotting, spasm, collateral circulation, etc., with the result that of necessity the treatment is superficial.

The chapter on anticoagulants is particularly good, being a careful and conscientious review of the present situation as indicated by the literature, but the contribution on cerebral ischaemia in pulmonary disease, which might well have been of great interest, is somewhat disappointing as it is limited to less than four pages.

LA PSYCHOPATHOLOGIE EXPÉRIMENTALE By F. H. Baruk. (Pp. 127. 4s. 3d.) Paris: Presses Universitaires de France. 1964.

This little book for the general reader provides a readable introduction to a number of topics in experimental psychopathology. Those most fully treated are experimental catatonia and certain aspects of psychopharmacology. Other chapters on experimental neuroses, on behaviour and initiative in animals and men, and on the problems of experiment in psychopathology are either rather skimpy or rather diffuse. The medical practitioner who wants a simple concise introduction to these important fields of research will probably find it better elsewhere.

BIOLOGICAL CLOCKS IN MEDICINE AND PSYCHIATRY By

C. P. Richter. (Pp. viii $+109 ; 103$ figures. \$6.50.)

Springfield, Illinois: Charles C. Thomas, 1965.

In these lectures Dr. Richter has put together in concise and handy form his findings and those of others, on the numerous periodicities of function which may be detected in healthy and, even more, in diseased animals and men. Whether each and every one of these, as it arises, should be taken as evidence for a 'clock' mechanism is hardly discussed and no consideration is given to the possibility of deriving one periodicity from another, or others in combination. Richter's own view is that periodicities which emerge only in morbid states represent a coming into synchrony of the responsible aggregate of cells, and this is a reversal of an evolutionary trend whereby the organism is progressively freed from the tyranny of primitive cyclic tendencies. He has, however, kept speculation to a minimum and the book is packed with fascinating data for the reader to brood on. It will be of interest to a very wide group of people.

\section{CORRECTION}

In the paper by J. G. McLeod (J. Neurol. Neurosurg. Psychiat., 1966, 29, 12) the phrase, 'and recordings were made in turn from each of the three electrodes' which appears in the first sentence, fifth paragraph, of the section on Methods, has been wrongly placed. It should be in the second sentence, fifth paragraph, which should read, "A condenser discharge of time constant $50 \mu \mathrm{sec}$. derived from a thyratron stimulator was applied to electrodes at the wrist and recordings were made in turn from each of the three electrodes with reference to a fourth electrode applied to the tip of the finger; the subject was earthed through the metal plate on the back of the hand.' 